\title{
An Architectural Self - Criticism:The Accessibility Analysis of Berlika Park Swimming Pool
}

\section{Abstract}

Urban designers and architects have to clearly understand the physical features and needs of the people they are designing for. In the designing process fields such as anthropometry, biomechanics, ergonomics, biology and physics require scientific verification. But it can easily be forgotten that there are physically-challenged persons. All users have to experience any place by using their ability to move and perceive. If designers don't take into account the special circumstances for physically-challenged persons, the accessibility of the places become impossible. At the same time a sustainable and an accessible place is truly a sign of urban rights. In this context, human rights are not only important for disciplines such as law, sociology, psychology and political sciences but also they must be important for design disciplines such as architecture, urban design and interior design. This research based on the rights to exercise for physically-challenged persons aims to analyze the accessibility of the place. The Facility-Berlika Park Swimming Pool-chosen for this study-was designed by DKN Yapı and I
Keywords: Accessibility, architecture, human rights, swimming pool, urban rights.

*Instructor, KTO Karatay University, Fine Arts and Design Faculty, Department of Architecture, Konya, Turkey.

E-mail: ozlem.demirkan@karatay.edu.tr 
was a member of the design team and today an active user of the facility. As a research method photographs were taken of different areas of the facility and the conformity of TSE standards -TS9111 - TS 12576 was discussed. Within this context, the structure was examined in terms of mobility constraints under the titles of accessible route, the arrangement of immediate surroundings of the building, arrangement of the entrance of the building, arrangement of the accessibility inside the building, signs, elevators, and fire emergency alert systems. The problematic areas of the building were identified and analyzed. This research aims to make case-study-building more accessible place and a new modification project has been planned. But it is necessary to examine the buildings or the environment during their design process and solve the problems without the need of renovation project. The design standards for everyone should be considered in the contracts. At the same time, the accessibility plates should be asked from the architects.

\section{INTRODUCTION}

Urban area exists in parallel with the experience capacities of all users. Architecture is one of the disciplines that users have a potential to increase the experience capacity. The urban sociologist Robert Park defined the city, as "man's most consistent and on the whole, his most successful attempt to remake the world he lives in more after his heart's desire" (Harvey, 2012). The degree of success should be measured by the architect's designing capacity for all users. Within this context, the right to the city is a right that can be demanded by all users (Lefebvre, 1972). According to Harvey, demanding the right to the city is the demand for decisive power on how the urban is shaped and reshaped during the process of urbanization. The respondents who demand the right to the city are not only the politicians but also the architects, interior architects, and urban planners, who are the practitioners of design principles. Adopted by the Congress of Local and Regional Authorities of the Council of Europe in 1992, the first European Urban Charter is important in terms of the urban and the right of urban citizens. Among its articles, it is suggested to provide a harmonious order among road users such as mass transportation, private cars, pedestrians, and bicyclers in order not to restrict the freedom of movement and mobility. It is also suggested to provide facilities of sport and leisure for everyone no matter what their age, ability and income is (Palabiyık, 2004). Within this context, meeting the right of sport for each individual and providing an accessible route for everyone is an urban must.

Impairment and disability is viewed from two theoretical background: The medical and the social (Bromley, Matthews, \& Thomas, 2007). When we look at the medical side, disability is 
defined as a physical or mental impairment that has a 'substantial' and 'long-term' negative effect on your ability to do normal daily activities (URL1). In contrast, the social model defines it as the restriction of physically handicapped or mentally retarded people in the environment they live in. At the same time, it involves the disabled people's recognition of their rights and abilities, finding job opportunities, being effective in politics, and their recognition of physical barriers around them. World Health Organization defines the social model as: The social model of disability, on the other hand, sees disability as a socially created problem and not at all an attribute of an individual. On the social model, disability demands a political response, since the problem is created by an unaccommodating physical environment brought about by attitudes and other features of the social environment (WHO, 2002).

As can be understood from the definitions, the real disability shows itself in social life. Poorly designed environments turn the impairment people into disabled people. Similarly, the Turkish Standards Institution view the definitions of impairment and disabled as two different terms. TSI 9111 defines the "impairment" as a person who has difficulties in adapting to the social life and in meeting daily needs due to the loss of physical, mental, psychological, sensory and social capabilities at various levels by birth or by any reason thereafter and who therefore needs special physical reforms in structures and areas. The impairment and disabled are two different terms. Disabled is defined as restriction or inexecution of roles expected from an individual in parallel with age, sex and social and cultural factors due to impairment or a disability. When the limitations of impairment constraint the social life, the impairment individual becomes disabled. TSI 9111 also explains the mobility constraints. According to TSI 9111, disabled, temporary disabled, elders, pregnant, people with baby carriage, children, people carrying heavy goods, enormous or overweight people and too tall or short people are in this group. The mobility constraints of people will be removed through accessibility arrangements on the environment including the buildings and their surroundings, and the mobility of people in this group will be possible, easy and comfortable (TS 9111, 2011).

Within this context, a number of theorists defines the disability as the constraints designed by the architect (Goldsmith, 1997). In their study investigating the accessibility of the city centrum by wheel chair, Bromley, Matthews and Thomas concluded that $60 \%$ of the users felt handicapped because of the planning faults as a result of 150 detailed interviews (Bromley et al., 2007). Evcil (2009) studied on the users of wheel chairs using analysis 
questions of Useh, Moyo, and Munyango, and she discussed the accessibility of state buildings in Istanbul for wheel chair users (Evcil, 2009).

When the literature is reviewed, it is seen that a variety of issues such as the examination of infrastructure mobility constraints of stadiums through EWA (ergonomic work analysis) method (Yazıgı, Resende, \& Yazıgl, 2015), the effort to understand the barriers of disabled people through interviews (S. Abdulkadir \& M Jamaludin, 2012; Lid \& Solvang, 2015; Taylor \& Jozefowicz, 2012) the inclusion of disabled children into the urban area (Abdou, 2011), the educational awareness (Evcil, 2012), state buildings and standards (S. Abdulkadir \& M. Jamaludin, 2012), and the mathematical calculation of accessibility (Church \& Marston, 2002) focused. All of these studies discus the accessibility. However, it is necessary to examine the building or the environment during its design process and solve the problems without the need of renovation project. At the same time, the managers, state, users and designers should be aware of the disabled individuals (Abdulkadir, Jamaludin, \& A., 2011). When the project process of state buildings and social facilities in Turkey is examined, it is seen that the projects are given to designers through direct supply or competitions. There is no article about meeting the accessibility conditions in the contracts. Therefore, the architects may not meet the accessibility requirements although they are mentioned by TSI.

\section{STANDARDS AND STATUARY REGULATIONS}

Turkish Standards Institution determined a variety of standards in order to eliminate the mobility constraints in urban and environment. The application of the standards in urban areas is necessary to provide the mobility. The local municipalities are required to make arrangements appropriate to the disabled individuals under the decree-law no 572. Some provisions about the accessibility (elimination of physical obstacles) are added to Zoning Legislation. Accordingly, pavements, walk ways, residence and public buildings are to be constructed in a way that is appropriate to the accessibility of the disabled people. The standards involve the practice details and material specification. TS accessibility standards are as follows (URL 2):

-TS 12576 Structural preventive and Sign (Pictograph) design criteria on street, boulevard, square and roads for disabled people and elderly persons in urban areas.

-TS 12460 Rail rapid transit system in urban part 5- design criteria of facilities for disabled and elderly people.

-TS 12574 Rail road transit system in urban areas Part 10: Graphs and signs in station 
-TS 12575 Rail rapid transit system in urban areas part 14: Design and layout criteria of station seats.

-TS 9111 Specifications for Designing Residential Buildings for the Disabled.

ICS .11 .180 .01 .9104030 Turkish Standard was prepared by TSI Construction Specialization Group and was accepted in 22 November 2011. The referenced standards involved TS 12576 Structural preventive and Sign (Pictograph) Design Criteria on street, boulevard, square and roads for handicaps and elderly persons in urban areas. The terms of impairment, disabled and mobility constraints are defined in content. Although the word "Physically challenged people" is suitable for these people worldwide. In this research the word impairment and disabled are used for physically challenged people according to TSI standards.

\section{SAMPLE AND METHOD}

Berlika Park Swimming Pool, which was tendered by Meram Municipality, was chosen as the case study since I was one of the project owners and in the design team during my working period as a company partner, chief executive and architect in DKN Structural Engineering - Architecture Limited Company in 2010. The facility is located in sheet number M28, block number 37362, plot 2 in Meram district of Konya. It is a $100000 \mathrm{~m}^{2}$ project with a two semi-olympic pools, wedding saloon about $6000 \mathrm{~m}^{2}$,landscape and a theater. Swimming Pool's construction is $6000 \mathrm{~m}^{2}$. The structure was constructed using reinforced concrete carcass. The facility was designed as two symmetrical pools. There are two semi-olympic pools, training pool, fitness center, pilates center, dressing rooms, bathrooms, showers, lifeguard rooms, Turkish baths, saunas, and steam rooms inside the building.

The facility was photographed in a specific route. This specific route was determined in accordance with the main items of TS9111 and TS 12576. First of all, the approach to the building was examined. Assuming that the disabled people would arrive at the facility using motor vehicles such as buses, bus stops were examined first. Then, road-pavement connections, approach to the building and the main entrance were examined respectively. Afterwards, help desk, dressing rooms, elevator, stairways and access to the pools inside the building were examined respectively. Within this context, the structure was examined in terms of mobility constraints under the titles of accessible route, the arrangement of immediate surroundings of the building, arrangement of the entrance of the building, arrangement of the 
accessibility inside the building, signs, elevators, and fire emergency alert systems.

The problematic points on the photos taken were marked according to the relevant TSI standard, which determines the problems. Renovation projects about the problematic points were prepared.

\section{ACCESSIBILITY ANALYSIS OF BERLIKA PARK}

Photograph 1. Approach to the Building (Demirkan, 2015)

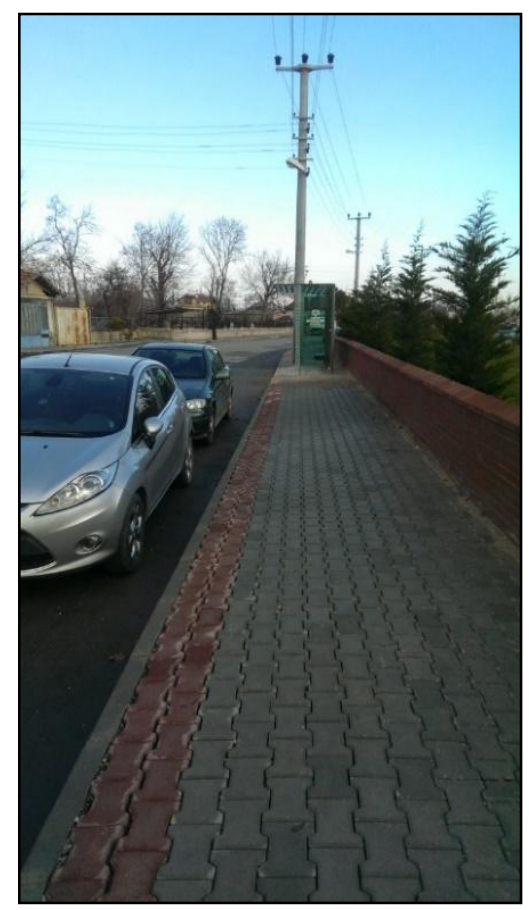

1. There is no handrail (TS 12576 Article 5.8).

2. There is no backrest above $45 \mathrm{~cm}$ of the seat (TS 12576 Article 5.5.1).

3. The width of the pavement is less than $300 \mathrm{~cm}$ in bus stops (TS 12576 Article 5.5.1).

4. It is not banned for other vehicles to stop or park within the bus stops by horizontal and vertical signs (TS 12576 Article 5.8). The information in the information board is missing.

5. No information about the route plan of each bus, the closest cabstand and important phone numbers on the information board (TS 12576 Article 5.8)

6. No tactile surface on the pavements (TS 12576 Article 5.1.5.1)

7. Power pole is in the middle of the pavement without any warning sign.

8. The curbstone isn't made with different material and color from the pavement overlay (TS 12576 Article 5.1.7.2).

9. The sidewalk of the bus stop isn't high enough, so there is a level difference between the pavement and the landing area (TS 12576 Article 5.8). 
10. No space for a wheelchair adjacent to the seats in the bus stop (TS 12576 Article 5.5.1.)

11. There is no shiny, colored and reflective strip with $15 \mathrm{~cm}$ thickness and at a level of 100 and $140 \mathrm{~cm}$ (TS 12576 Article 5.8).

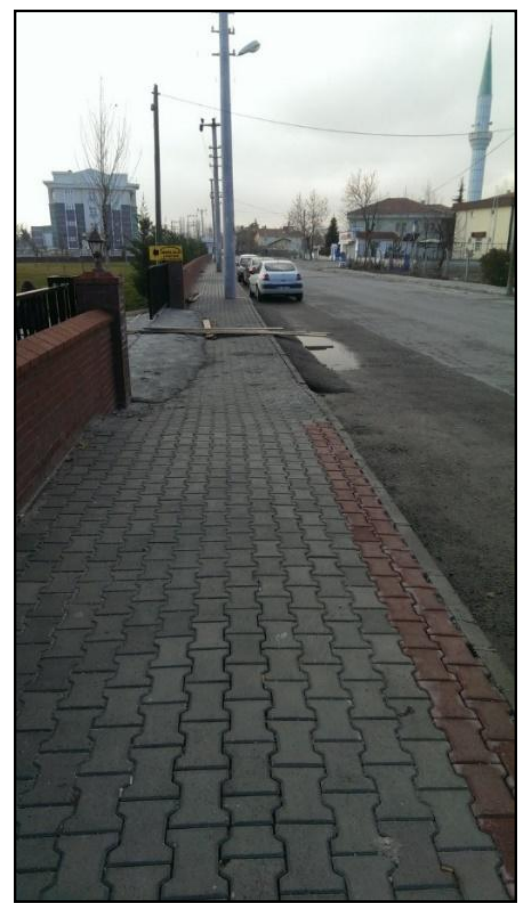

Photograph 2. Approach to the Building (Demirkan, 2015)

1. The guideboards aren't made of flat material and there isn't enough lighting (TS 1257 Article 5.6) (TS 9111 Article 4.8.6)

2. The screws used for the setup of power poles and traffic signs to the ground aren't arranged so that they aren't dangerous for the pedestrians (TS 12576 Article 5.1.7.1)

3. When the sidewalk behind the ramp isn't between 90 and 122 $\mathrm{cm}$, a ramp of $1: 12(8 \%)$ should have been built in order to decrease the height of the pavement (TS 9111 Article 4.4.3.1) (TS 12576 Article 5.2)

4. No roadblocks are placed on the curbstone to prevent the car parking.

5. The ramps (above 5\% slope) aren't covered with firm, nonskid and slightly rough material (TS 12576 Article 5.2.3).

6. There is no yellow-black warning sign is present during maintenance and repairs (TS 12576 Article 5.6).

7. No signing for the visually impaired individuals at the start and end of the ramps (TS 9111, Article 4.4.3.4)

8. The curbstone isn't made with different material and color from the pavement overlay (TS 12576 Article

9. No drainage gutter and grate on it to remove the surface water (TS 12576 Article 5.1.7.3)

10. In the event of maintenance and repair on the pavement, there is no audial and light warning, and the maintenance area 
isn't surrounded with an obstacle at least $10 \mathrm{~cm}$ height (TS 12576 Article 5.1.6)

11. On two sides of the $150-\mathrm{cm}$ pavement, there is no emergency lanes, $50 \mathrm{~cm}$ on the curbstone side and 25 on the property side (TS 12576 Article 5.1.1)

Photograph 3. Approach to the Building (Demirkan, 2015)
Figure 1. Plan of the park area (Demirkan, 2012)

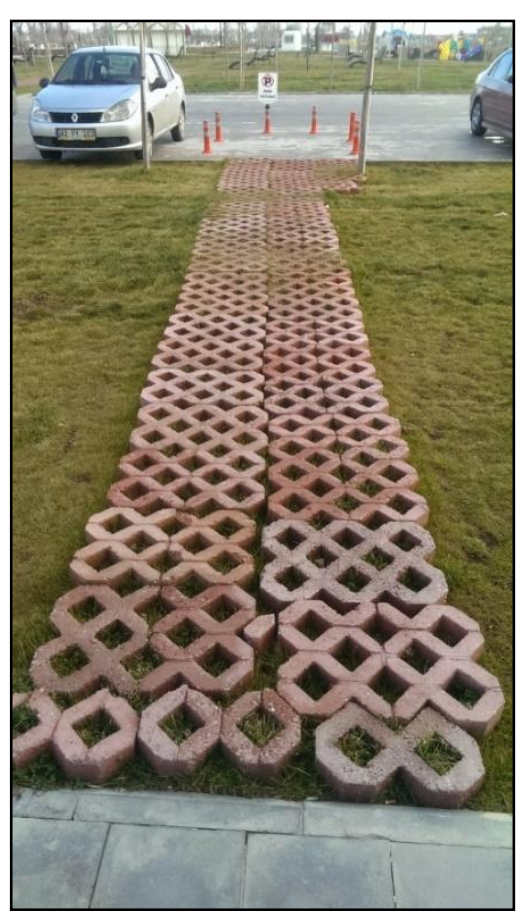

1. The signs and symbols aren't perceivable and there is no information with braille alphabet. Similarly, they aren't visually understandable for hearing impaired individuals. (TS 12576 Article 5.6)(TS 9111 Article 4.8.15)

2. There is no sign, which shows the accessible routes, on walkways, important cross-roads and parks (TS 12576 Article 5.6)

3. The use of inappropriate material for the access from parking lot to the building

4. There is no at least one accessible route from bus stop, accessible parking lot, accessible kiss and ride zone, streets and pavement to the accessible entrance of the building (TS 9111 Article 4.3.1)

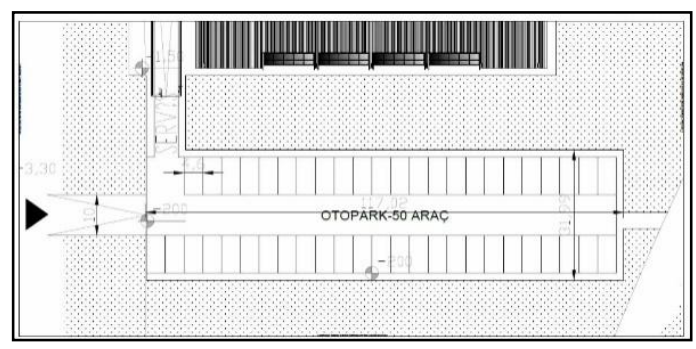




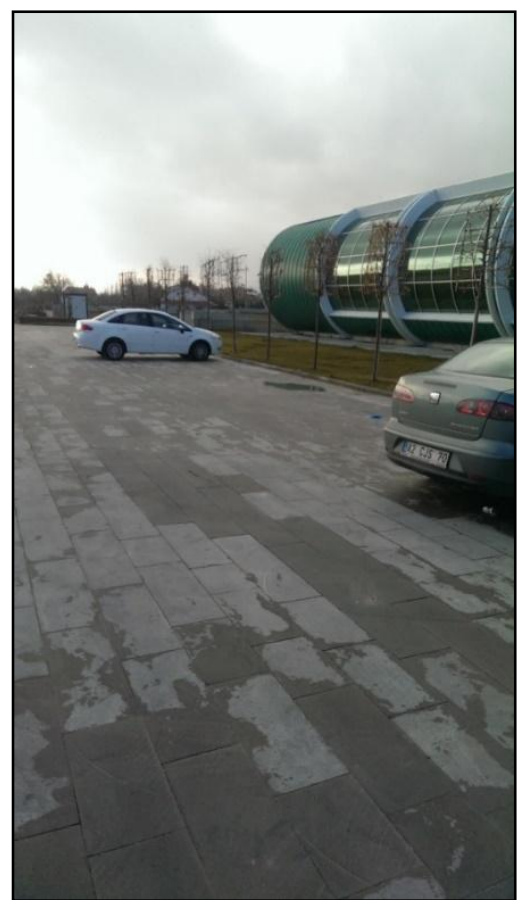

Photograph 4. Approach to the Building (Demirkan, 2015)

1. The parking lot for disabled individuals isn't protected against weather conditions such as snow and ice (TS 9111, Article 4.4.1) 2. The ratio of handicapped parking space is less than 5\% (TS 9111, Article 4.4.1) (TS 12576 Article 5.7)

3. There is no secure kiss and ride zone that has an access to the building (TS 9111, Article 4.4.1)

4. The size, quality and the signs of handicapped parking lot cannot by questioned (TS 9111, Article 4.4.1)

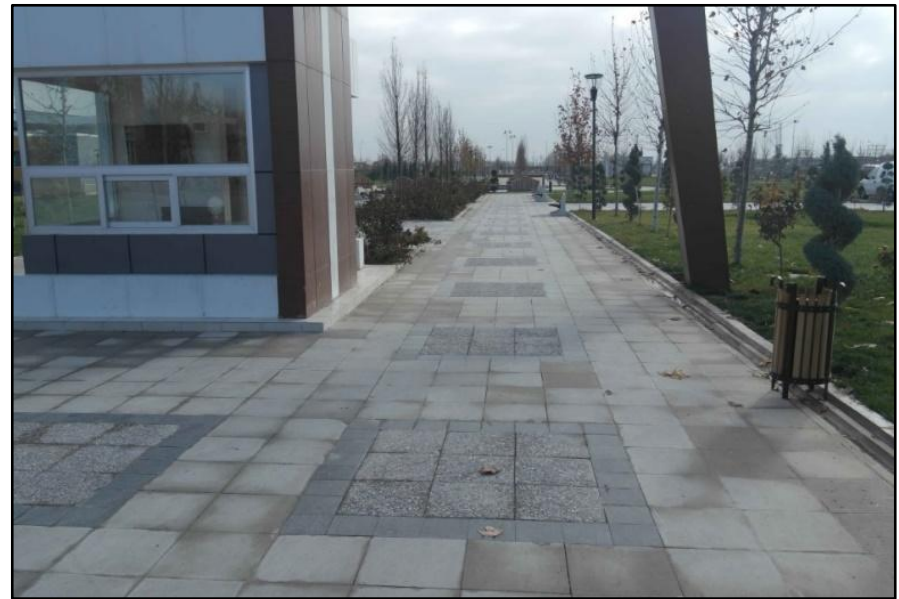

1.There is no additional lights or opposite colors and information board with perceivable surface at important decision-making points, which would help find the way or provide orientation (TS 9111, Article 4.4.2.2)

2.The walkways to the buildings around and between the buildings have straight, firm and non-skid (wet/dry) surface and free of drainage grate (TS 9111, Article 4.4.2.2)
Photograph 5. Approach to the Building (Demirkan, 2015) 
3. There is no visual, audial and perceivable information boards in the site with the aim of orientation and finding way (TS 9111, Article 4.4.2.2)

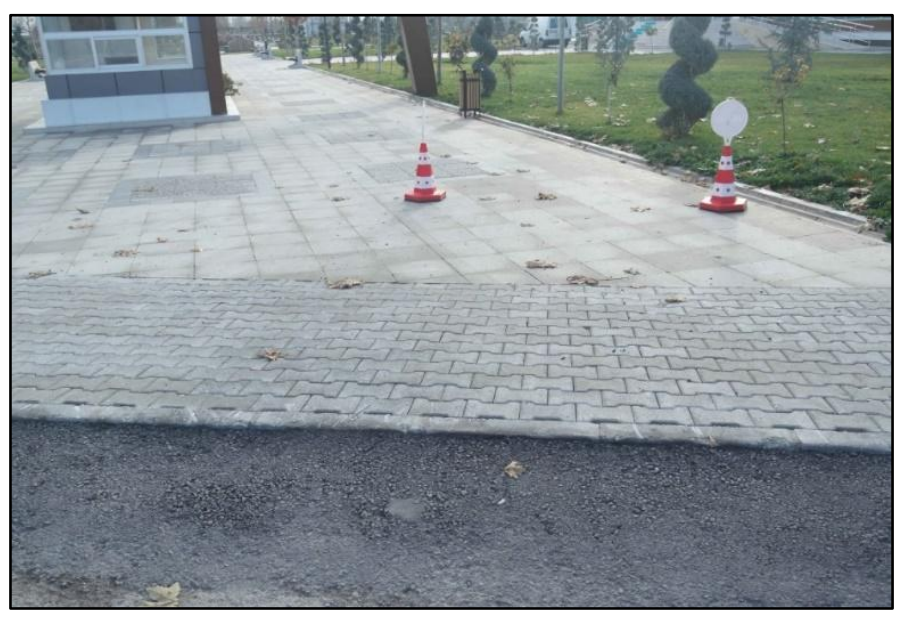

1. In front of the ramp, there is no floor covering of $60 \mathrm{~cm}$ wide on three sides of the pavement which shows the ramp (TS 9111 Article 4.4.3)

2. The perceivable surfaces don't have opposite colors with their surroundings

3. There is no at least one accessible route from bus stop, accessible parking lot, accessible kiss and ride zone, streets and pavement to the main entrance of the building (TS 9111 Article 4.3.1)

4. There is no perceivable surface on the pavement (TS 12576 Article 5.1.5.1

5. The ramps (above 5\% slope) aren't covered with firm, nonskid and slightly rough material with different colors (TS 12576 Article 5.2.3)

6. The height of curbstone isn't between 3 and $15 \mathrm{~cm}$

7. There is no perceivable warning surface on the ramp which decreases the height of the pavement (TS 9111 Article 4.11.1.3) 8. There is no roadblocks are placed on the curbstone to prevent the car parking.

9. When the sidewalk behind the ramp isn't between 90 and 122 $\mathrm{cm}$, a ramp of $1: 12(8 \%)$ should have been built in order to decrease the height of the pavement (TS 9111 Article 4.4.3.1) (TS 12576 Article 5.2) 

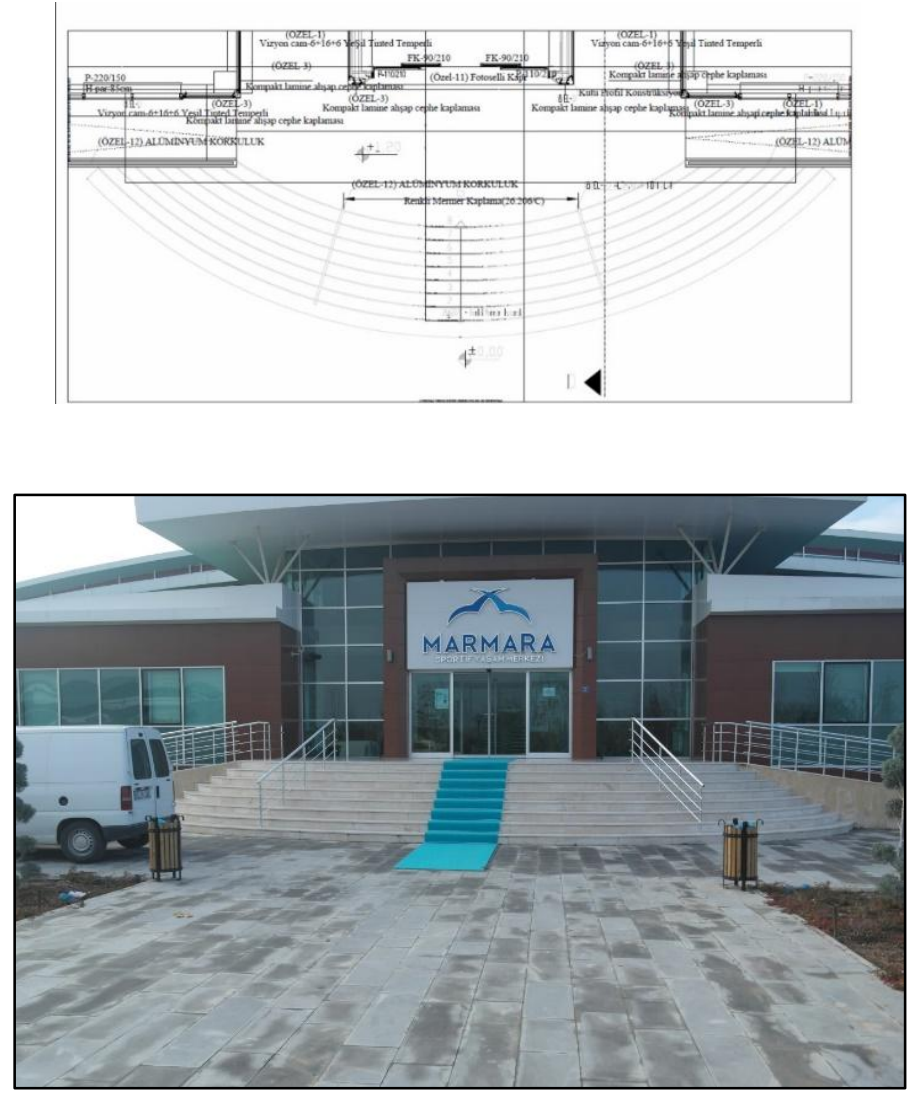

1. There are safety rails on both sides of the exterior stairway (TS 12576, Article 5.3)

2. There is no warning surface at the beginning and the end of the stairway (TS 12576 Article 5.3.2)

3. The front of the steps should be nosing and round (TS 12576 Article 5.3.3)

4. When the width of the stairs is more than $300 \mathrm{~cm}$, there should have been a safety rail in the center of the stairs

5. The points of the rails aren't open, and they aren't in U shape (TS 12576 Article 5.3.3) (TS 9111, Article 4.7.1.3.3)

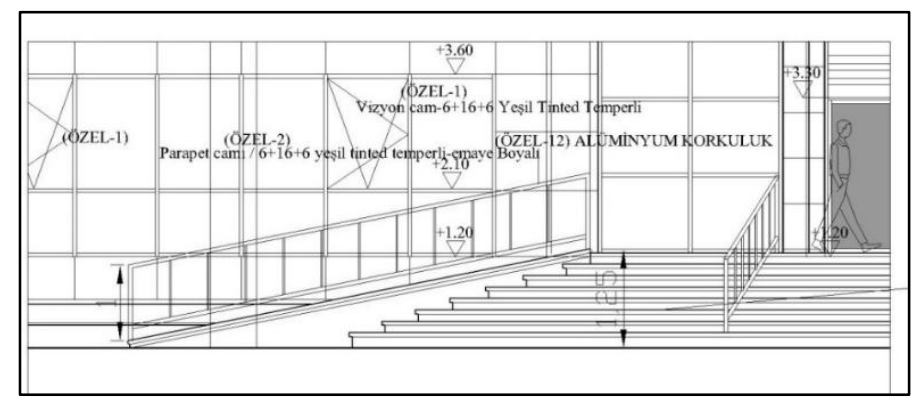

Figure 2. Entrance

(Demirkan, 2012)

Photograph 7. Approach to the Building (Demirkan, 2015)

Figure 3. Ramp

(Demirkan, 2012) 
Photograph 8. Ramp (Demirkan, 2015)
Photograph 9. Ramp (Demirkan, 2015)

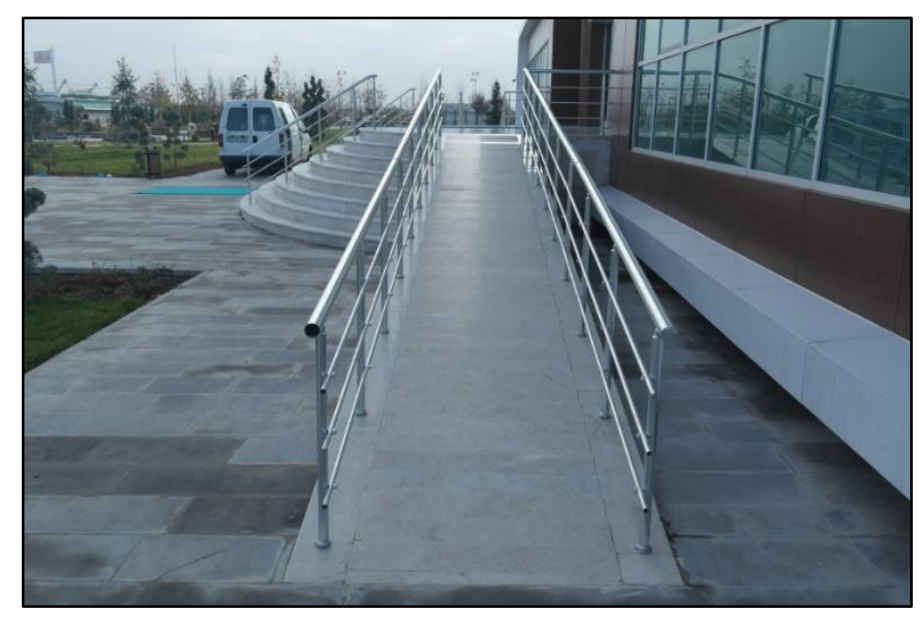

1. When the level difference is more than $100 \mathrm{~cm}$, the slope of the ramp should have been 1:16

2. When the level difference is more than $100 \mathrm{~cm}$ after the ramp ends, the slope of the ramp should have been 1:16 and it should have been $30 \mathrm{~cm}$ longer (TS 9111)

3. The width of the ramp is $130 \mathrm{~cm}$ (TS 9111 Article 4.4.3.2)

4. The rail doesn't go $30 \mathrm{~cm}$ more than the ramp in the beginning of the ramp (TS9111, Article 4.4.3.4)

5. There is no first level rail of $70 \mathrm{~cm}$ height on the both sides of the ramp (TS 9111, Article 4.4.3.4)

6. There are second level rails of $90 \mathrm{~cm}$ height on both sides of the ramp (TS 9111, Article 4.4.3.4)

7. The ramp sign isn't consistent with the international signs (TS12576 Article 5.6)

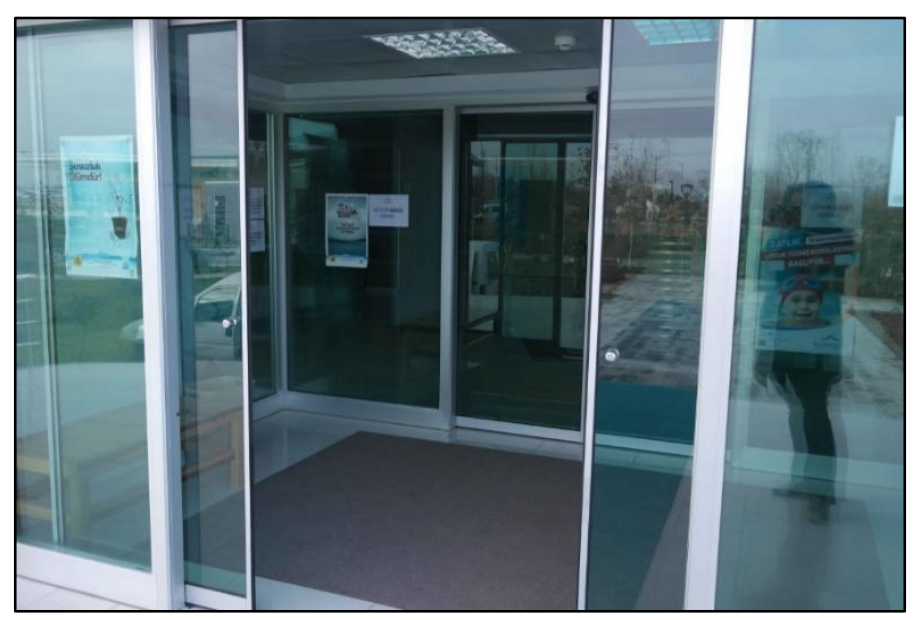

1. The floor coverings are made of slippery materials (TS 9111, Article 4.6.1)

2. The carpet is thinner than $1.3 \mathrm{~cm}$ 


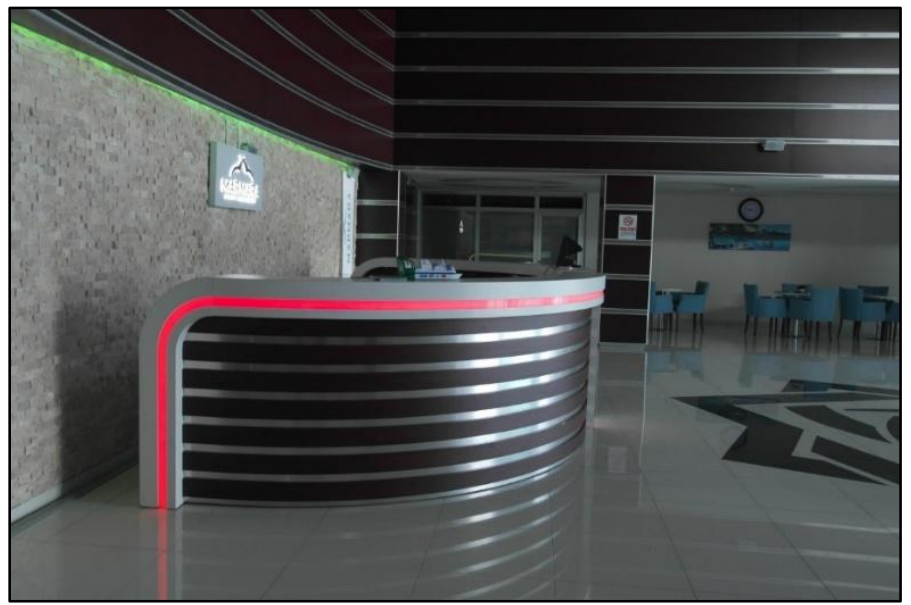

Photograph 10. Information desk (Demirkan, 2015)

1.There is no at least one disabled information desk which is 90 $\mathrm{cm}$ width and $86 \mathrm{~cm}$ height (TS 9111, Article 4.10.3.2)

2. The floor coverings are made of slippery materials (TS 9111, Article 4.6.1)

3. There isn't a foldable shelf system on the desk, on which the disabled people can write (TS 9111, Article 4.10.3.2)

4. The necessary equipment isn't labeled by signs for hearing impaired individuals (TS 9111 Article 4.8.15)

5. There is no guidance plan or floor plan near the main entrance

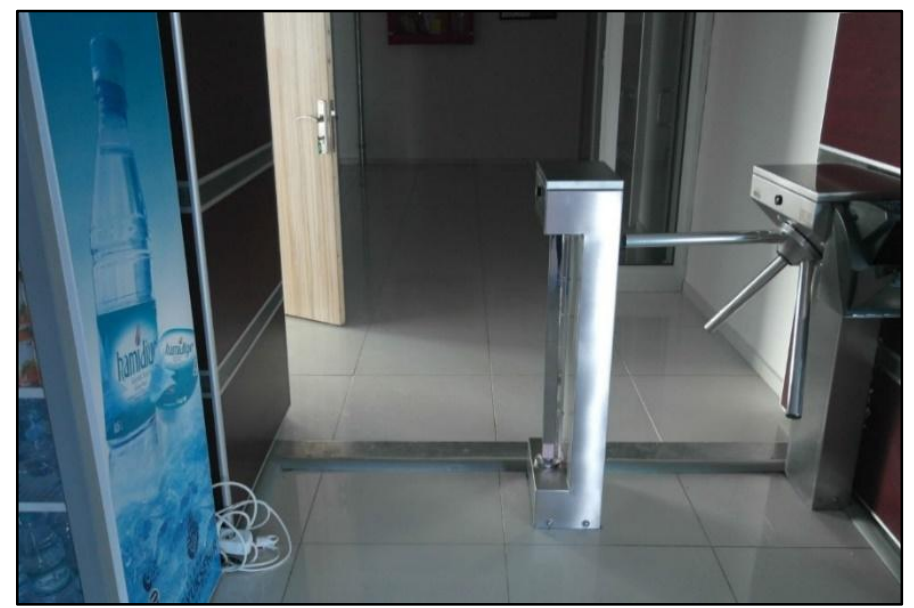

Photograph 11. Entrance to the pool (Demirkan, 2015)

1.There isn't a space of $90 \mathrm{~cm}$ width and $220 \mathrm{~cm}$ height without obstacles inside the corridors. 
Photograph 12. Elevator (Demirkan, 2015)

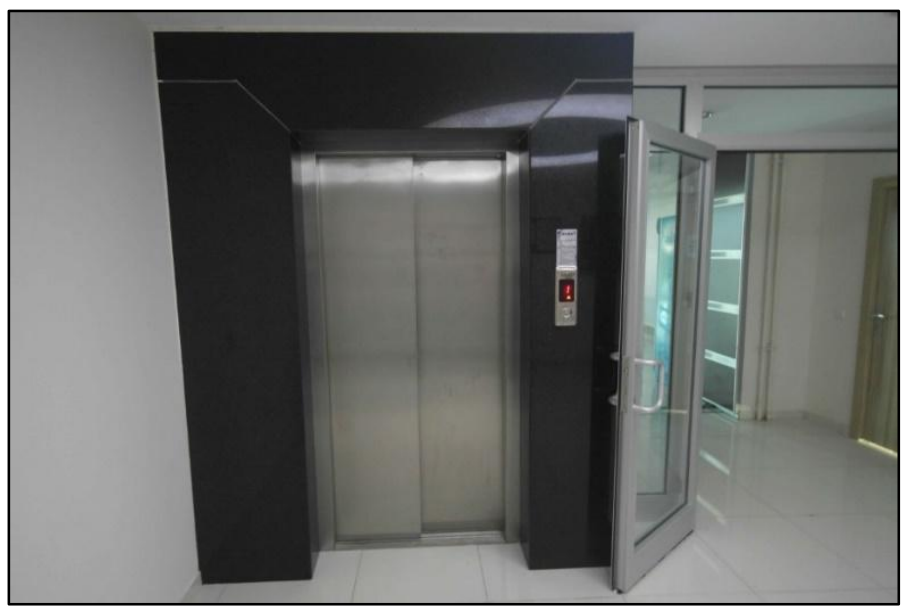

1. There isn't a space of $122 \mathrm{~cm}$ width and $76 \mathrm{~cm}$ deep for approach from the side (TS 9111, Appendix A).

2. There isn't two-way communication systems in the elevators (TS 9111, Appendix B)

3. The elevator call panel isn't placed between the height of 90 $\mathrm{cm}$ and $137 \mathrm{~cm}$. TS 9111, Article 4.7.1.2

4. The size of the elevator cage doesn't fit the size of $150 \mathrm{~cm}$ width and $150 \mathrm{~cm}$ height (TS 9111, Article 4.7.1.2)

5. There is no accessible elevator (with all qualities) sign (TS 9111, Article 4.7.1.2)

4. There is no evacuation elevator in the building (TS 9111, Article 4.2)

5. There is no warning "don't use elevators during fire" in the elevator since there isn't an evacuation elevator. (TS 9111, Appendix B)

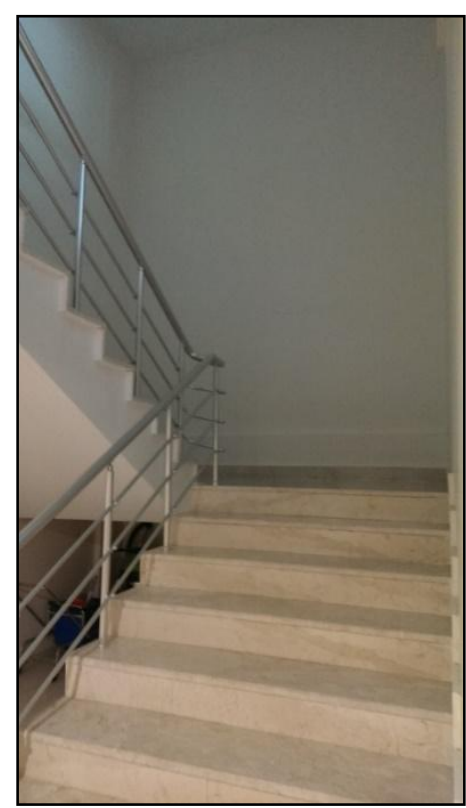


1.There is no information signs with braille on the railings.

* Since there isn't warning surface on the landing, warning tapes aren't placed on landing in rectangle and shape and crosswise *The stairs doesn't fit the formula of $2 a$ (riser) $+b$ (the depth of stair) $=60-64 \mathrm{~cm} *$ No landing for each 8- 10 stairs (TS 9111, Article 4.7.1.3)

2. There is no $30 \mathrm{~cm}$ and $60 \mathrm{~cm}$ length perceivable surface at the end and beginning of the stairs and on the landing, respectively (TS 9111, Article 4.7.1.3)

3. There is no non-skid tape on any of the stairs (TS 9111, Article 4.7.1.3) The stair material is composed of slippery and shiny materials (TS9111, Article 4.7.1.3)

4. There is no visual warning tape (preferably yellow) on the first and last stairs of stairway and on the landing (TS 9111, Article 4.7.1.3)

5.The front of the stairs is nosing (TS 9111, Article 4.7.1.3).

6. There is no rail at the height of $70 \mathrm{~cm}$ on the railings (TS 9111, Article 4.7.1.3)

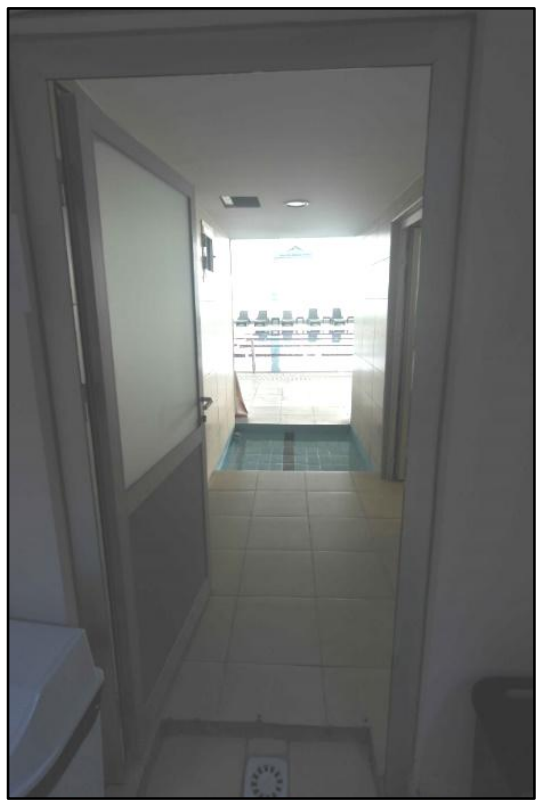

Photograph 14. To the pool (Demirkan, 2015)

1.There isn't a space of $90 \mathrm{~cm}$ width and $220 \mathrm{~cm}$ height without obstacles inside the corridors.

2. Floor coverings are made of slippery materials (TS 9111, Article 4.6.1) 
Photograph 15. Toilets (Demirkan, 2015)

Figure 3. Baths (Demirkan, 2015)

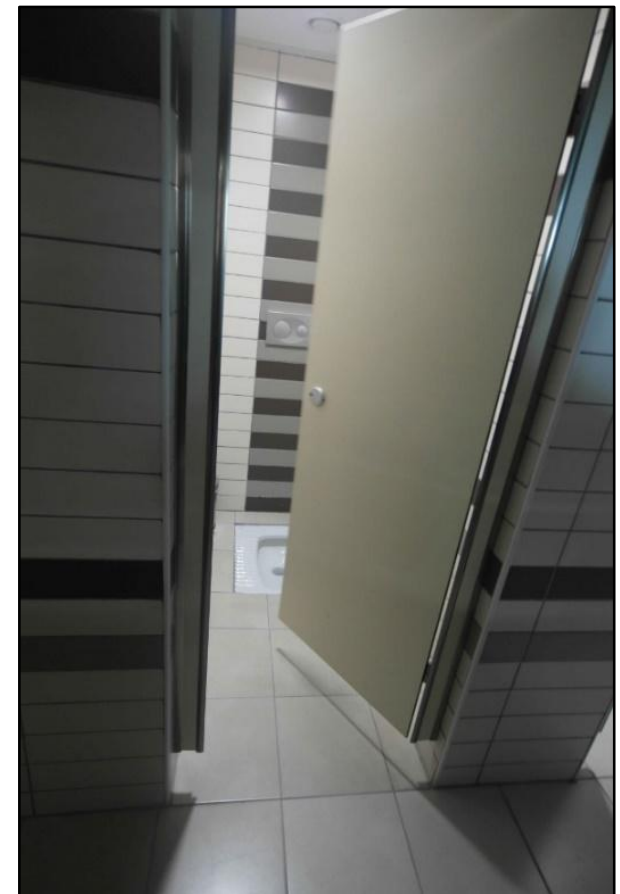

1. There is no protective plate of $40 \mathrm{~cm}$ height under the door. (TS 9111, Article 4.6.2)

2. Floor coverings are made of slippery materials (TS 9111, Article 4.6.1)

3. There is no $U$ shape pushing handle between the height of 80 and $110 \mathrm{~cm}$ on bathroom doors (TS 9111, Article 4.6.2)

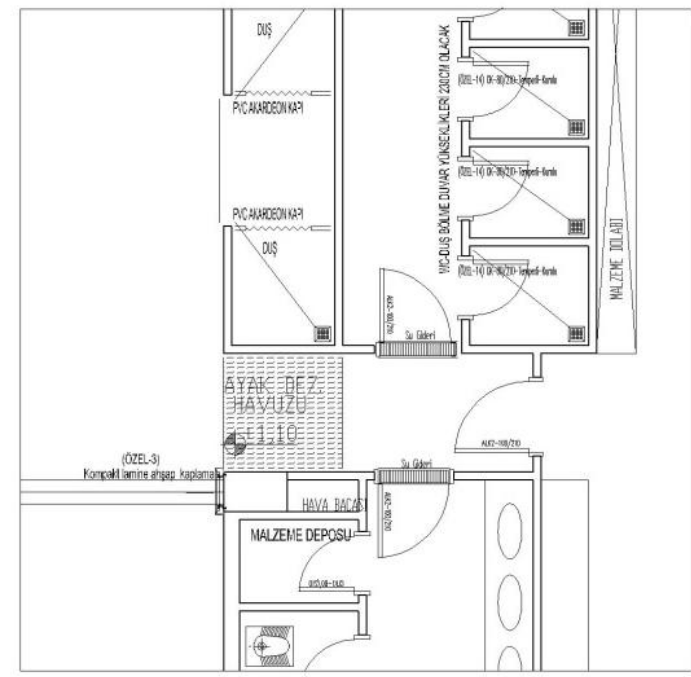




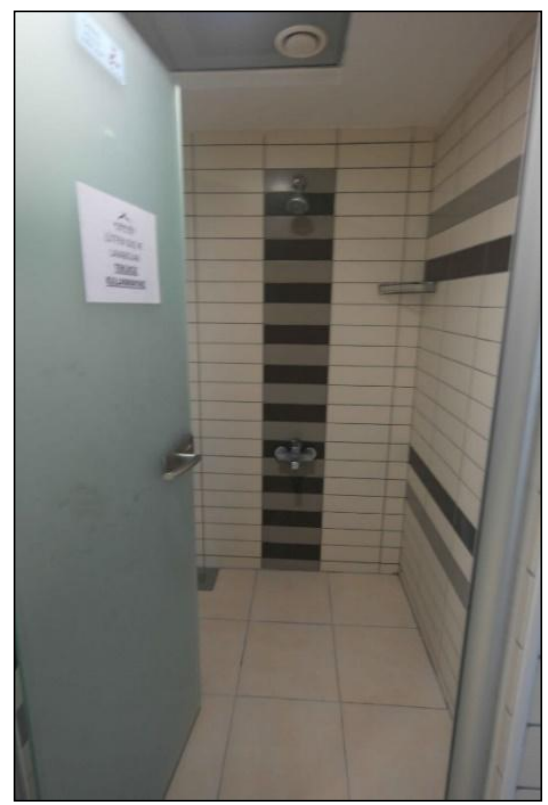

Photograph 16. Baths (Demirkan, 2015)

1. The height of the soap dispenser isn't between 80 and $110 \mathrm{~cm}$ (TS 9111, Article 4.7.3).

2. The doors are made of glass and there is no singing for visually impaired individuals (TS 9111, Article 4.6.2).

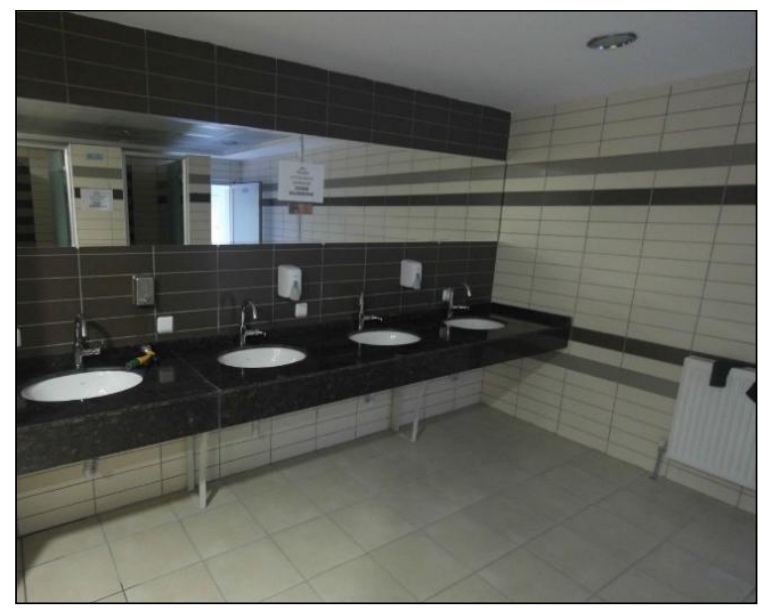

Photograph 17. Baths (Demirkan, 2015)

1. The distance from sink to tap is more than $30 \mathrm{~cm}$ (TS 9111, Article 4.7.3).

2. There is no enough space under the lavatory so that a wheelchair could enter (20 cm depth $75 \mathrm{~cm}$ height) (TS 9111, Article 4.7.).

3.The height of the lavatory front from the floor is more than 86 cm (TS 9111, Article 4.7.3).

4. The floor covering is slippery (TS 9111, Article 4.6.1). The height of the bottom of the mirror from the floor is more than 90 cm (TS 9111, Article 4.7.3.)

5.The height of the soap dispenser from the floor isn't between 80 and $110 \mathrm{~cm}$ (TS 9111, Article 4.7.3) 
6. There is no handle bar on the edges of the lavatory for people who have difficulty in standing * The height of tissue dispenser or hand dryer from the floor isn't between 80 and $110 \mathrm{~cm}$ (TS 9111, Article 4.7.3.).

Photograph 18. Hamam (Demirkan, 2015)

Photograph 19. Pool (Demirkan, 2015)

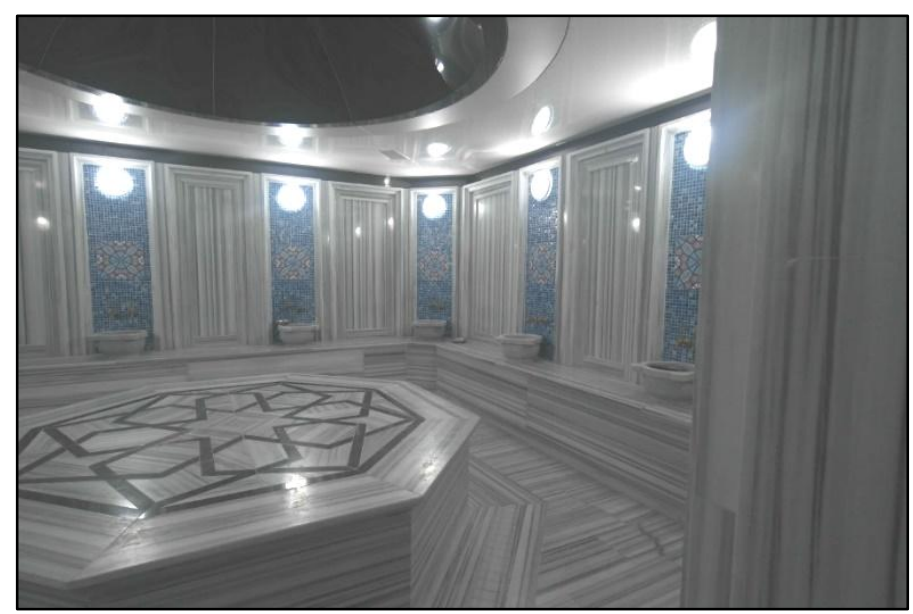

1.The doors are made of glass and there is no singing for visually impaired individuals (TS 9111, Article 4.6.2)

2 . There is an obstacle of $4 \mathrm{~cm}$ height on the entrance.

3. There is no visible alarm system.

4. There is no hearable audio alarm (TS 9111 Article 9.1)

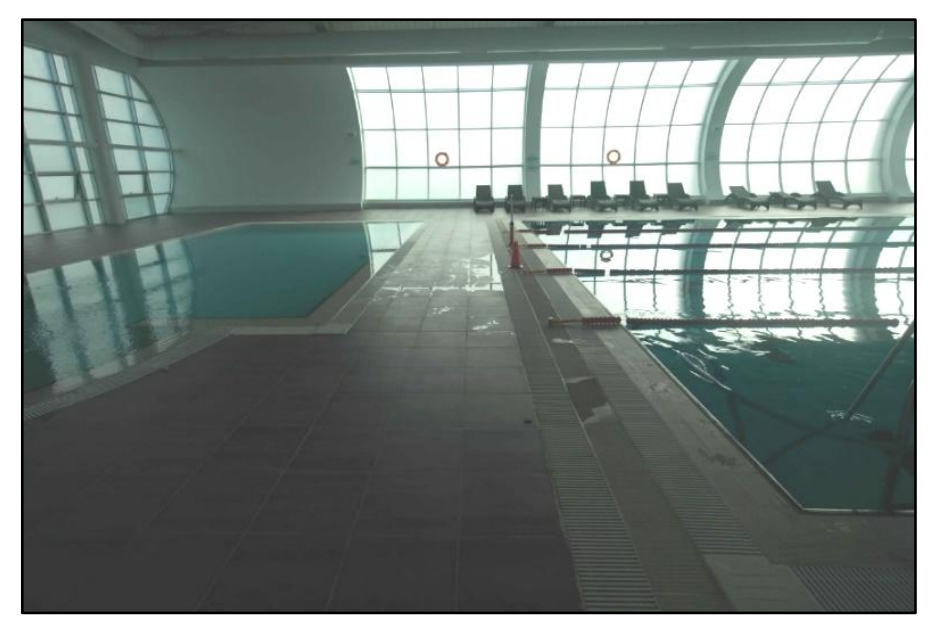

1. There is no hearable audio alarm. Article 9.1

2. There is no visible alarm system.

3.There is no necessary warning sign.

4.There is no perceivable floor. (TS 12576 Article 5.1.5.1)

5.There is no pool elevator or lift for disabled individuals. 


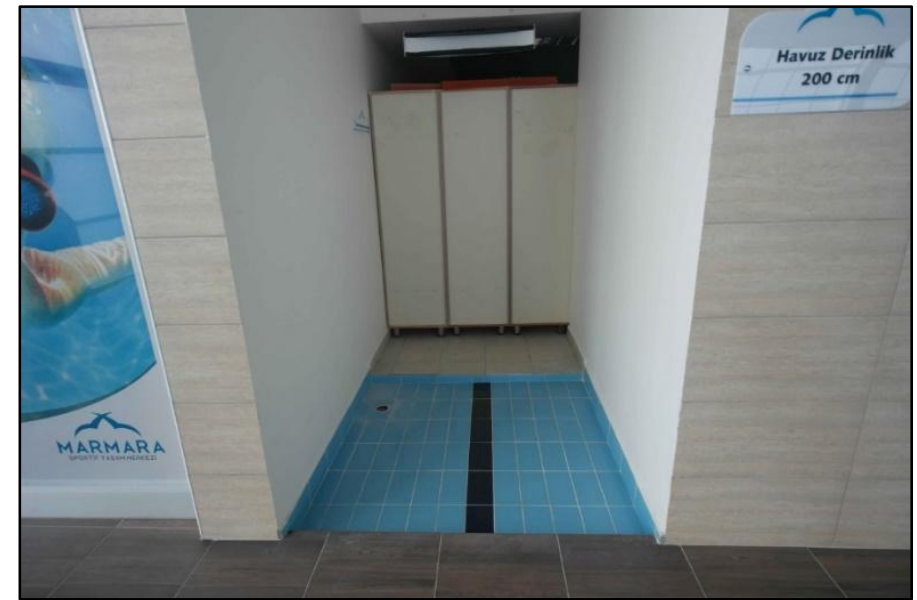

1.The guideboards aren't made of flat material and there isn't enough lighting (TSE, 2011)

2.There are obstacles on accessible route. One of the pool entrance is cancelled; a locker is placed there.

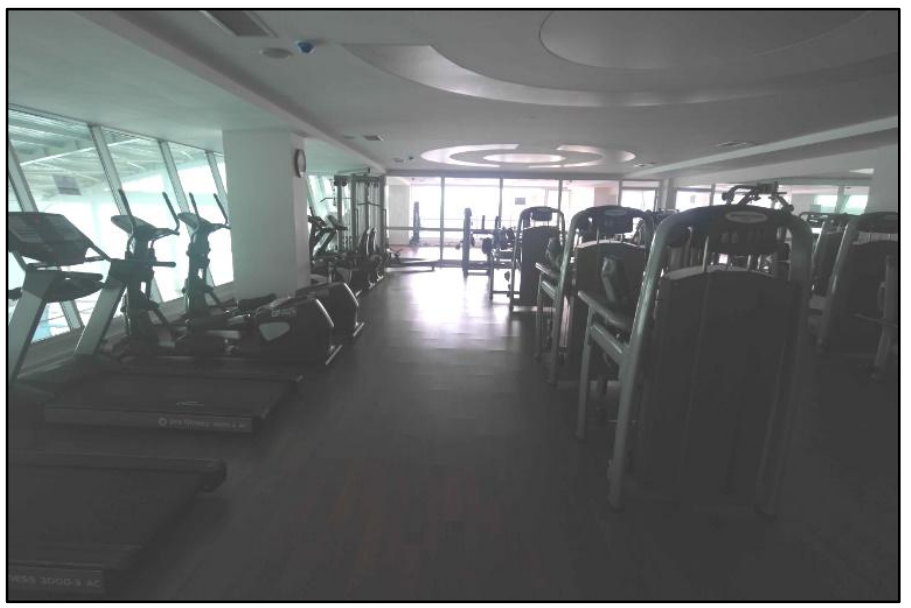

1.There is not enough information about fire exit.

2 .There isn't enough room for maneuver of wheelchair

3. The place hasn't got enough lighting.

4. There is an obstacle on the way to the terrace.

5 . There is no necessary warning sign.

6. The necessary warning boards and signs that show the fire exit is absent.

\section{CONCLUSION RECOMMENDATIONS}

The problems about accessibility of the building are caused by the lack of measures taken during project and construction process. The project provision doesn't involve the route to the building. Moreover, there are ramps on the route, which weren't in the project. Within this context, some changes have to be made on the accessible route to the building. The bus stop and the height of the pavement have to be redesigned in accordance with
Photograph 20. Pool

(Demirkan, 2015)

Photograph 21. Fitness (Demirkan, 2015) 
TSI standards. The necessary signboards should be placed on the bus stop. It is a must that there should be at least one accessible route to the building. Therefore, the necessary measures should be taken about approach to the building. Since the width of the stairs on the entrance is 6 meters, an additional railing should be placed on the stairs. The railing and the handrails should be designed on 70 and $90 \mathrm{~cm}$, and the hand rail should be $30 \mathrm{~cm}$ longer. The width of the ramp is appropriate but the slope is not. The ramp should be reconstructed. In the interior space, the floor material should be non-skid and perceivable. Also, necessary arrangements for visually impaired and people with wheelchairs should be done on the information desk. According to TSI standards, the current elevator should be replaced by an accessible one. The elevation differences on the floor should be restored. The necessary signings should be placed around the pool. Also, pool elevator for disabled people should be placed, and the necessary signalization measures should be taken against emergency. On the first floor, the elevation differences between fire-escape stairs and fitness saloon should be rearranged using stairs and ramp. Fitness equipment should be rearranged by considering the maneuver room for the individuals with wheelchairs.

Within this context, the relevant renovation projects were prepared for the structure. On the ground floor, the space between two showers was used for a new shower for disabled people. At least one accessible route was provided on the renovation projects. Some arrangements were done about building entrance, interior space accessibility, signings and elevator.

When we consider the developments in Turkey, it can be said that the governments are now more conscious about the accessibility than the past. The accessibility is tried to be provided especially in public buildings by renovation projects. However, these efforts are limited by placing an accessible elevator, and this isn't enough. Therefore, it is necessary to examine the building or the environment during its design process and solve the problems without the need of renovation project. The projects are given to designers through direct supply or competitions. However, there is no article about meeting the accessibility conditions in the contracts. The design standards for everyone should be considered in the contracts. At the same time, the accessibility plates should be asked from the architects. It is recommended that the government units and local governments along with the experts should check the accessibility plates during the project process. A control mechanism which will operate during the construction process should be formed. 
An Architectural Self - Criticism: The Accessibility Analysis of Berlika Park Swimming Pool

\section{REFERENCES}

Abdou, S. M. I. (2011). Inclusion of Physically Disabled Children Through Environmental Rehabilitation of Urban Spaces Case Study: Al Azhar park Caario. Procedia Engineering, 21, 53-58.

Abdulkadir, S., \& Jamaludin, M. (2012). Applicability of Malaysian Standarts and Universal Design in Public Buildings in Putrajava. Procedia Social and Behavirol Sciences, 36, 659669.

Abdulkadir, S., \& Jamaludin, M. (2012). Users' Satisfaction and Perception on Accessibility of Public Buildings in Putrajava: Access Audit Story Paper presented at the Asean Conference on Enviroment-Behaviour Studies, Bangkok Thailland.

Abdulkadir, S., Jamaludin, M., \& A., R. A. (2011). Building Managers' Perception in Regards to Accessibility, and Universal Design Implementation in Public Buildings:Putraja Case Studies. Procedia Social and Behavirol Sciences, 35, 129-136.

Bromley, R. D. F., Matthews, D. L., \& Thomas, C. J. (2007). City Centre accessibility for wheelchair users: The consumer perspective and the planning implications. Cities, 27(3), 229-230.

Church, R. L., \& Marston, J. R. (2002). Measuring Accessibility for People with a Disability. Geographical Analyses, 35(1), 8396.

Evcil, A. N. (2009). Wheelchair Accessibility to Public Buildings in İstanbul: Disability and Rehabilitation. Assistive Technology, 4(2), 76-85.

Evcil, A. N. (2012). Raising Awareness about Accessibility. Procedia Social and Behavioral Sciences, 47, 490-494.

Goldsmith, S. (1997). The New Paradigm: Designing for Disabled. Bath, Great Britain: Architectural Press.

Harvey, D. (2012). Asi Şehirler: Metis Yayınları.

https://www.gov.uk/guidance/equality-act-2010-guidance. (2010). Equality Act. Retrieved 03.2016, 2016

Lefebvre, H. (1972). Şehir Hakkl: Eğitim Bilim Toplum.

Lid, I., \& Solvang, K. P. (2015). (Dis)ability and the Experince of Accessibility in the Urban Enviroment Alter. European Journal of Disability Research, 366, 1-14.

Palabiyı,, H. (2004). Avrupa Kentsel Şart, Avrupa Konseyi Yerel ve Bölgesel Yönetimler Kongresi Anlaşmaları: Birleşik Yayınları.

Taylor, Z., \& Jozefowicz, I. (2012). Intra-Urban Daily Mobility of Disabled People for Recreational and Leisure Purposes. Journal of Transport Geography, 24, 155-172.

TS 9111 2011, Institute of Turkish Standards, The requirements of accessibility in buildings for people with disabilitiesand mobility constraints, ICS 11.180.01; 91.040.30.

WHO. (2002). Towards a Common Language for Functioning, Disability and Health ICF (pp. 9). Geneva: World Health Organization. 
Yazıgı, S., Resende, A. E., \& Yazıgl, R. (2015). Acceesibility in Soccer Stadiums:Infrastructure and Organization in Support of People with Reduced Mobility:A Use Analysis. Procedia Manufacturing, 3, 55557-55561.

URL1 https://www.gov.uk/guidance/equality-act-2010guidance, 2010

URL2 https://intweb.tse.org.tr/standard/standard/standardara. aspx

\section{Resume}

1991-1998 Meram Anatolian High School, 1998-2003 Gazi University Department of Architecture, 2003-2005 Master Degree Gazi University/Architecture (The Research of The Relation Between Structure And Ornament in Architecture) 2003-2015 DKN Yapı Mühendislik Mimarlık Sanayi Ve Tic. Ltd Şti. (Company partner/architect) 2013-2015 Phd Selçuk University/Architecture 2015 PhD KTO Karatay University /Architecture, 2015 Lecturer KTO Karatay University Department of Architecture 